\title{
Prevalence of Eosinophilic/Non Eosinophillic Nasal Polyps and Analysis of Their Presentation in Hospital Universiti Sains Malaysia Kelantan, Malaysia.
}

\author{
Ramiza Ramza Ramlia, Irfan Mohamad ${ }^{\mathrm{a}}$, Yahia Hussein Al-Hadeethi ${ }^{\mathrm{b}}$ \\ ${ }^{a}$ Department of Otorhinolaryngology-Head and Neck Surgery, School of Medical Sciences, Universiti Sains \\ Malaysia Health Campus, 16150 Kota Bharu, Kelantan, Malaysia. \\ ${ }^{b}$ Department of Otorhinolaryngology-Head and Neck Surgery, International Islamic University Malaysia, \\ Jalan Hospital, 25100 Kuantan, Pahang, Malaysia.
}

\begin{abstract}
Introduction: This study is aimed to examine the predominant inflammatory cells in nasal polyps (NP) in the local community and its correlation to the clinical presentations. Materials and Methods: The study was done retrospectively looking at patients who had undergone functional endoscopic sinus surgery (FESS) in Hospital Universiti Sains Malaysia (HUSM), Kelantan, Malaysia with a histopathological diagnosis of nasal polyposis (NP), between the years 2004 to 2008. Sixty two patients between the ages of 18 years to 60 years old were selected and data relevant to the study were collected from the patient's folders using a specially created form prepared for the study. The NP histopathology report from each patient underwent FESS were analysed and the patients were divided into eosinophilic and non eosinophilic dominant group. Clinical presentations from each patient were also gathered and analysed according to the NP group. Results: In HUSM, there were a higher number of eosinophilic types NP as compared to the neutrophilic type NP which is contrary to other study conducted on Asian populations. The clinical symptom correlations between either eosinophilic or non-eosinophilic type of NP have not shown any significant associations. Conclusion: The study showed that the incidence of histological subtypes of nasal polyp in HUSM is almost the same as that found in other parts of the world (Europe and North America) which will reduce the possibility of racial or geographical influence on the pathogenesis of the nasal polyp. Clinical symptoms and presentation alone are not enough to differentiate the type of the nasal polyp without the histological study.
\end{abstract}

Key words: Nasal polyposis, eosinophilic, non eosinophilic

\section{INTRODUCTION}

The prevalence of nasal polyps (NP) in the adult European and US population is about $2.7 \%$ and $1-4 \%$, respectively ${ }^{1,2}$. NP shows gender predominance with male to female ratio of $2: 1^{3}$. Pearlman et.al observed that NP most commonly presented in patients' age between 40-60 years old while patients over 80 years of age were unlikely to have NP. They also noted that the mean age at diagnosis was 51 years old in males and 49 years old in females ${ }^{4}$.

Between $19 \%$ and $36 \%$ of patients with chronic rhinosinusitis were reported to have NP ${ }^{2}$. Symptoms of NP include bilateral nasal blockage, nasal discharge and facial pain or pressure. In addition, it also causes loss of smell, headache and reduced general well-being ${ }^{5}$. The relationship between sinusitis and the nasal polyps is critical whereby the

Corresponding Author

Dr. Ramiza Ramza Ramli

Department of Otorhinolaryngology-Head and Neck

Surgery, School of Medical Sciences,

Universiti Sains Malaysia Health Campus,

16150 Kota Bharu, Kelantan, Malaysia.

Email: ramizaramza@usm.my

Telephone Number: 6012-9085767

Fax Number: 609-7676424 inflammation is believed to be the trigger to the polypoidal formation and part of the spectrum for chronic rhinosinusitis ${ }^{3}$.

Histologically, NP is covered predominantly by respiratory pseudostratified epithelium with ciliated and goblet cells. NP consists of loose connective tissue, oedematous stroma and inflammatory cells. The oedematous stroma contains inflammatory cells which are mainly eosinophils, neutrophils, mast cells, plasma cells, lymphocytes, monocytes, fibroblasts and macrophages ${ }^{6}$. The predominant inflammatory cells found in NP are eosinophilia consisting around $80-90 \%{ }^{7,8}$.

In a Caucasian population, NP has been shown to have a strong eosinophilic component ${ }^{5}$ whereas NP in Asian population shows a neutrophilic pattern'. However, the clinical presentation of NP remains similar between Asians and Caucasians.

This study is aimed to examine the predominant inflammatory cells in nasal polyps in the local community and its correlation to the clinical presentations. 


\section{MATERIALS AND METHODS}

The study was done retrospectively looking at patients who had undergone functional endoscopic sinus surgery (FESS) in Hospital Universiti Sains Malaysia (HUSM), Kubang Kerian, Malaysia with a histopathological diagnosis of nasal polyposis, between the years 2004 to 2008. Ethical clearance for this study was obtained from the Human Ethics Committee of Universiti Sains Malaysia. Sixty two patients between the ages of 18 years to 60 years old were selected and data relevant to the study were collected from the patient's folders using a specially created form prepared for this purpose. All the subjects are Malay, the dominant ethnic group in Kelantan. The details gathered from the form include demographic data, the initial clinical symptoms and signs, histology of the NP, radiological findings and treatment modalities. Patients with concurrent nasal diseases other than nasal polyps were excluded from the study.

The data were analysed using the Statistical Package for the Social Sciences (SPSS) version 18. Descriptive analyses were used to describe the means, standard deviations, frequency and percentage. To compare the clinical symptoms exact Fisher test and STATA software was used. The level of significance was set at 0.05 . If the $p$-value is less than 0.05 it will be considered statistically significant.

\section{RESULTS}

\section{Nasal Polyps (NP)}

The NP were graded clinically into three grades depending on its relation to the middle turbinate 10. About half of the patients had grade $2 \mathrm{NP}$ $(n=30)$; NP which extends inferiorly from the middle meatus beyond the inferior margin of the middle turbinate. The other half of the patients had grade $1 \mathrm{NP}(\mathrm{n}=15)$; polyps seen confined within the middle meatus and grade 3 NP ( $n=17)$ where the polyps extended beyond the middle meatus and touching the nasal floor (Figure 1). Fifty one patients had bilateral NP and only 11 patients had unilateral diseases which represent around $18 \%$ of the study sample. The gender ratio was 36 females to 26 males. The age range was from 15 to 76 years old with the mean was 45.1 years.

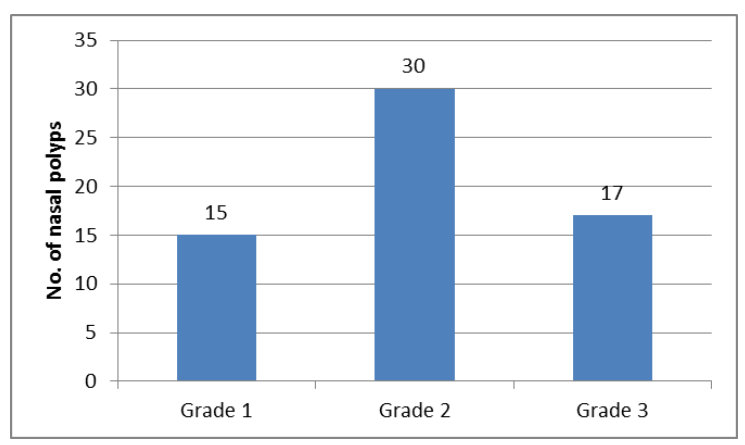

Figure 1: Number of patients vs. grade of nasal polyp

\section{NP and inflammatory cells}

Based on the histological findings from the histopathology report, the patients were then divided into two main groups, the eosinophilic and the non eosinophilic group. Fifty four $(87 \%)$ patients had eosinophilic type polyps (Figure 2). The histopathology report in HUSM routinely did not state the type and amount of the non eosinophilic inflammatory cells. It measures only the dominant percentage of either eosinophilic or non eosinophilic group.

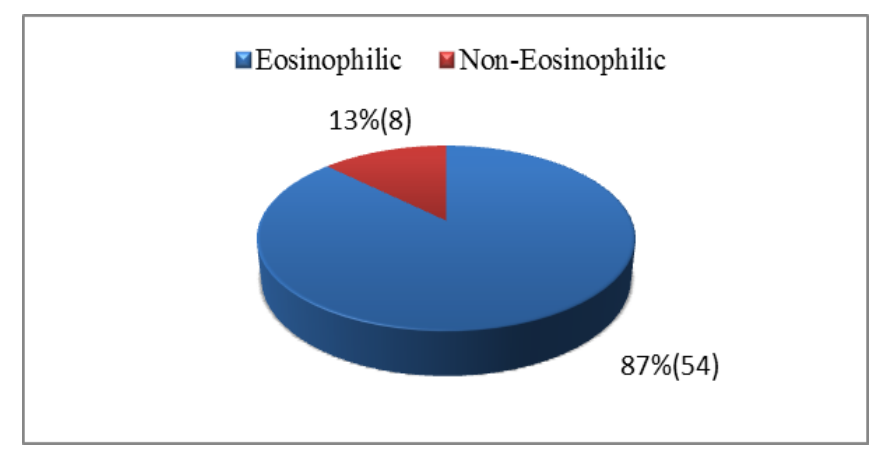

Figure 2: The subtype of nasal polyposis

\section{NP and symptoms}

Symptoms documented from the patients include nasal blockage, reduction in smell and rhinorrhea. Both eosinophilic $\mathbf{( 9 2 . 6 \% )}$ and non eosinophilic (87.5\%) type NP group showed almost a similar percentage of nasal blockage presentation (Table I). A total of 44 patients from both groups have reduced smell. There were no significant association between nasal polyp type and symptoms of reduction in smell and rhinorrhea (Table I).

Table I: The association between NP symptoms and the type of NP

\begin{tabular}{|c|c|c|c|c|}
\hline & & \multicolumn{2}{|c|}{ Polyp type } & \multirow{2}{*}{$\begin{array}{l}\text { Fisher's } \\
\text { exact } \\
\text { test }\end{array}$} \\
\hline & & $\begin{array}{l}\text { Eosino- } \\
\text { philic }\end{array}$ & $\begin{array}{c}\text { Non } \\
\text { eosino- } \\
\text { philic }\end{array}$ & \\
\hline \multirow{2}{*}{$\begin{array}{c}\text { Nasal } \\
\text { blockage }\end{array}$} & Present & $\begin{array}{c}50 \\
(92.6 \%)\end{array}$ & 4 (7.4\%) & \\
\hline & Absent & 7 (87.5\%) & $\begin{array}{c}1 \\
(12.5 \%)\end{array}$ & \\
\hline \multirow{2}{*}{$\begin{array}{c}\text { Smell } \\
\text { abnormality }\end{array}$} & Present & $\begin{array}{c}39 \\
(72.3 \%)\end{array}$ & $\begin{array}{c}15 \\
(27.7 \%)\end{array}$ & \\
\hline & Absent & $5(62.5 \%)$ & $\begin{array}{c}3 \\
(37.5 \%)\end{array}$ & \\
\hline Rhinorhea & Present & $45(83 \%)$ & $9(16.7 \%)$ & 0.623 \\
\hline
\end{tabular}




\section{DISCUSSION}

Retrospectively NP patients in HUSM have a higher number of eosinophilic types NP as compared to the non eosinophilic type NP. It correlates well with studies among the western populations where eosinophilic were the dominant inflammatory cells. The eastern Asian populations on the other hand, have a dominant non eosinophilic type $\mathrm{NP}^{11}$. In HUSM, the histopathological report only gave the total percentage of inflammatory cell types either eosinophilic or non eosinophilic type. The report did not calculate and analyze each inflammatory cell in the non eosinophilic group.

Zhang et al. attempted to further characterize the variations seen in Asian polyps. Polyp tissue samples from 27 Chinese patients from the Guangdong province of China were harvested. The samples were compared to a group of matched Caucasian Belgian patients, where Chinese polyps had a significantly lower incidence of eosinophils ${ }^{12}$. Studies in China and Japan showed that the predominant inflammatory cells in NP were the neutrophilic type $^{11,13}$.

In this study, the clinical symptom correlations between either eosinophilic or non eosinophilic type of nasal polyps have not shown any significant associations. None of the symptoms presented were able to differentiate between both types of NP. Zhang et al. also reported in their study that there were similarity in symptom presentation between the Chinese and the Belgian group of patients ${ }^{12}$.

The youngest patient in our study was 15 years old and the oldest was 76 years old. The peak of the presentation was in the 4th and 5th decade and noted to decline on both extremities of age. These findings correlate with reported literature ${ }^{14}$. The number of male $(n=26)$ and female $(n=36)$ patients in this study resembles an earlier study by Settipan et al. In their review of 211 NP patients, there was an almost equal distribution of males and females, 50.2 and $49.8 \%$, respectively ${ }^{15}$ but results from the more recent literature suggested that higher male to female ratio. The male: female ratio of patients with NP was 2.9 in ages 40-50 and maximal at 6.0 for patients between $80-89$ years of age ${ }^{2,4}$.

In contrary to other studies on Asian population, this study showed a higher eosinophilic type NP as compared to the neutrophilic type NP. We also concluded that the type of NP whether it is eosinophilic or non eosinophilic type, have no significant association with the clinical presentation of NP patients in HUSM. A similar study conducted in Japan has also concluded the same result and suggested the use of other parameters such as CT Scans, blood test and the presence of co-morbid allergic diseases which yield more accurate findings ${ }^{16}$. In most previous studies, patient with dominant eosinophilic type NP have a poor prognosis and more recurrence rates as compared to the non eosinophilic type $\mathrm{NP}^{17}$, therefore other parameters suggested by Sakuma et al. should be studied in order to predict the type of NP and hence determining the success of the subsequent management of NP.

\section{CONCLUSION}

HUSM has a higher number of eosinophilic types of NP similar to prevalence studies in the western population. The types of NP whether it is eosinophilic or non eosinophilic type, have no significant association with the patients' clinical presentation of NP in HUSM. The symptoms and clinical presentation is not dependent on the histology of the nasal polyp.

\section{CONFLICT OF INTEREST: None}

\section{ACKNOWLEDGEMENTS}

This study was supported by the Division of research and innovation, Universiti Sains Malaysia through the Incentive grant scheme for lectures. The author would also like to thank the School of Medical Sciences and Hospital Universiti Sains Malaysia record office for providing their assistance and participation.

\section{REFERENCES}

1. Rosenfeld RM, Andes D, Bhattacharyya N, et al. Clinical practice guideline: adult sinusitis. Otolaryngol Head Neck Surg. 2007; 137(3):36577.

2. Larsen K, Tos M. The estimated incidence of symptomatic nasal polyps. Acta Otolaryngol. 2002; 122(2):179-182.

3. Gleeson M et al. Section XI: The nose and paranasal sinuses, (eds) Scott-Brown's Otolaryngology, Head \& Neck Surgery', 7th edition, Edward Arnold Ltd, London. 2008; 1549 - 1557.

4. Pearlman AN, Chandra RK, Conley DB, Kern RC. Epidemiology of Nasal Polyps. Nasal Polyposis (eds.) T.M. Önerci and B.J. Ferguson, SpringerVerlag Berlin Heidelberg. 2010; 9-15.

5. Bachert C, Wagenmann M, Rudack C., et al. The role of cytokines in infectious sinusitis and nasal polyposis. Allergy. 1998; 53(1): 2-13.

6. Fokkens W, Lund VJ, Mullol J. European position paper on rhinosinusitis and nasal polyps. Rhinology Suppl. 2007; 20:1-136.

7. Ikeda K, Shiozawa A, Ono N, Kusunoki T, Hirotsu M, Homma H, Saitoh T, Murata J.

Subclassification of chronic rhinosinusitis with nasal polyp based on eosinophil and neutrophil. Laryngoscope. 2013; 123:E1-E9.

8. Nakayama T, Yoshikawa M, Asaka D, Okushi T, Matsuwaki Y, Otori N et al. Mucosal eosinophilia and recurrence of nasal polyps-new classification of chronic rhinosinusitis. Rhinology. 2011; 49:392-396. 
9. Jareoncharsi P, Bunnag C, Muangsomboon S et al. Clinical and histopathological classification of nasal polyps in Thais. Siriraj Hosp Gaz. 2002; 54:689-697.

10. Lund VJ, Holmstrom M, Scadding GK. () Functional endoscopic sinus surgery in the management of chronic rhinosinusitis. An objective assessment. J Laryngol Otol. 1991; 105:832-5.

11. Ishitoya J, Sakuma Y, Tsukuda M. Eosinophilic chronic rhinosinusitis in Japan. Allergol Int. 2010; 59:239-245.

12. Zhang N, Holtappels G, Claeys C et al. Pattern of inflammation and impact of Staphylococcus aureus enterotoxins in nasal polyps from southern China. Am J Rhinol. 2006; 20:445-450.

13. Cao PP, Li HB, Wang BF et al. Distinct immunopathologic characteristics of various types of chronic rhinosinusitis in adult Chinese. J Allergy Clin Immunol. 2009; 124(3):478-84.

14. Grigoreas C, Vourdas D, Petalas K et al. Nasal polyps in patients with rhinitis and asthma. Allergy Asthma Proc. 2002; 23:169-174.

15. Settipane, G. A. Allergy and Asthma Proceedings: Epidemiology of Nasal Polyps Volume 17, Number 5, OceanSide Publications, Inc. 1996; 231-236.

16. Sakuma $Y$, Ishitoya J, Komatsu $M$ et al. New clinical diagnostic criteria for eosinophilic chronic rhinosinusitis. Auris Nasus Larynx. 2011; 38(5):583-8.

17. Hancer TS, Kasapoglu F, Demir UL, Ozmen OA, Coskun, HO, Basut. Correlation between clinical findings and eosinophil/neutrophil ratio in patients with nasal polyps. Eur Arch Otorhinolaryngol. 2014; 272:917-921. 